\title{
Evaluation of Employment Competitiveness of City-based and Application-oriented College Graduates and a Comparative Analysis of Their Differences-A Case Study of Beijing Union University
}

\author{
Liping Jiang ${ }^{1}$, Bin $\mathrm{Li}^{2}$, Keqiang $\mathrm{Wu}^{3} \&$ Ning $\mathrm{Yan}^{4}$ \\ ${ }^{1}$ Biochemical Engineering College, Beijing Union University, Beijing, P.R. China \\ ${ }^{2}$ Business College, Beijing Union University, Beijing, P.R. China \\ ${ }^{3}$ Management College, Beijing Union University, Beijing, P.R. China \\ ${ }^{4}$ Psychological Counseling Center, Beijing Union University, Beijing, P.R. China \\ Correspondence: Ning Yan, Psychological Counseling Center, Beijing Union University, 100101, Beijing, P.R. \\ China. Tel: 86-10-6594-0794. E-mail: libinpsy@126.com
}

Received: October 23, 2019

doi:10.5539/ass.v15n12p131
Accepted: November 13, 2019

Online Published: November 19, 2019

URL: https://doi.org/10.5539/ass.v15n12p131

\begin{abstract}
As a city-based and application-oriented college, Beijing Union University focuses on cultivating application-oriented talents to meet the needs of city development. In recent years, the number of college graduates has increased, the demand for talents has become increasingly high, and the employment situation for graduates has become increasingly grim. This paper takes the 2019 graduates of Beijing Union University as the objects of investigation, and conducts research on the employment competitiveness of graduates through questionnaires and interviews. It is found that in terms of environment adaptability and the concept of employment, there are significant differences among graduates from different registered permanent residences and habitual residences; Party members and females have significantly higher levels of professionalism and foreign language proficiency than those of non-Party members and males; and the family income of graduates from Beijing and who live in cities is relatively better. Based on the existing research results, some suggestions have been made for both individual college graduates and higher education institutions.
\end{abstract}

Keywords: application-oriented, city-based, difference, employment competitiveness

\section{Introduction}

According to the latest information released by the Ministry of Education, college graduates reached 8.34 million in 2019, surpassing 8.2 million in 2018. With the number of college graduates reaching a record high, this has created the most difficult employment season in history. As an important factor affecting the employment of college graduates, the employment competitiveness is the cornerstone for college students to achieve a smooth transition to employment and sound development. It is also one of the fundamental ways to effectively solve the increasingly serious employment situation for college graduates in China.

The concept of employment competitiveness was first proposed by British economist Beveridge in 1909. At present, there are two main definitions of employment competitiveness: the first emphasizes the ability to obtain a job at the time of initial employment, and considers employment competitiveness to be the ability to successfully obtain a job, maintain and upgrade one's existing occupation (Anne et al., 2013). Chinese scholar Zhao Jun (2015) also believes that employment competitiveness is the ability to have a career. The second view pays more attention to the impact of employment competitiveness on individuals, businesses and the entire economic society. Oliver (2015) proposes that employment competitiveness is the skills, understanding and personal qualities that both undergraduates and graduates can acquire and continually improve, thereby motivating them to find or create jobs that benefit individuals, the labor market, and the social economy. Meanwhile, Chinese scholar Lou Xijin, Zhou Shuhong, and Wu Liyu (2005) believe that employment competitiveness is not only the ability to overcome the competition, find a suitable job, and the ability to realize one's own value in a job. And based on the degree of influence on the student produced by various factors at the time of employment, he divides employment competitiveness into three different levels, core competitiveness, 
basic competitiveness and environmental competitiveness, and this has been recognized by most Chinese scholars.

In recent years, Chinese scholars have done a lot of research on the employment competitiveness of college students. Overall, the level of employment competitiveness of domestic college graduates is not high, and the structure of employment competitiveness is uneven (Shao, Zhao, Huang, \& Cao, 2019). From the perspective of core competitiveness, graduates have insufficient learning ability, creative thinking ability, and decision-making capacity (Li \& Cheng, 2018), and most students lack the ability to apply theory to practice (Chen, 2018); from the perspective of basic competitiveness, having a lack of social ability and imperfect career planning constitute a concrete manifestation of weak employment competitiveness of graduates (Chen, 2019). Meanwhile, biased self-awareness and insufficient job-seeking experience are important reasons for lacking employment competitiveness (Ma Mengyao, 2018); from the perspective of environmental competitiveness, graduates from families with financial difficulties have relatively weak professional ability development, and they don't have clear self-awareness on career development ( $\mathrm{Li}, 2019)$.

There are two main factors affecting the employment competitiveness of college graduates: First, from the perspective of personal factors of graduates, Liu Xiaoyu (2008) notes gender, age, political affiliation, registered permanent residence, nature of household, graduate school and academic qualifications as factors affecting employment competitiveness of graduates. Second, from the perspective of school, Cao Yuxia (2017) points out that the nature and reputation of school, curriculum, and level of teaching are important factors influencing employment competitiveness of graduates.

Beijing Union University aims to build city-based and application-oriented higher education institutions and focuses on cultivating application-oriented talents to meet the needs of city-based development. It is a key application-oriented talent training base in Beijing, and cultivates many talents every year for the country, especially for the capital, Beijing. With the increase in the number of graduates and the rapid development of the economic society, enterprises are increasingly demanding talents, and we hope that new employees can be integrated into the work as soon as possible. In order to meet the needs of enterprises and to help Beijing Union University graduates gain better employment, it is necessary to improve the employment competitiveness of graduates.

\section{Research Design and Sample}

\subsection{Research Object}

This study takes 2019 graduates from Beijing Union University as the research object, with a total of 6047 students, including 2378 males accounting for $39.33 \%$, and 3,669 females accounting for $60.67 \%$; 3,817 students from Beijing accounting for $63.12 \%$, and 2,230 students from outside of Beijing accounting for $36.88 \%$; 3,627 students of science accounting for $59.98 \%$, and 2,420 students of liberal arts accounting for $40.02 \%$.

\subsection{Method}

Questionnaire method was used to investigate the employment competition of Beijing Union University graduates. At the same time, we interviewed individual graduates on their career intentions, employment situation, difficulties faced when job hunting and the help provided by their school.

The questionnaire is divided into two parts. The first part covers the basic situation and is divided into five aspects: gender, major, political affiliation, registered permanent residence and habitual residence.

The second part investigates the employment competitiveness of graduates. Taking the classification of employment competitiveness by Lou Xijin et al. (2005) as a reference, starting from the three levels of core competitiveness, basic competitiveness and environmental competitiveness, this paper investigates the employment competitiveness of Beijing Union University graduates. The core competitiveness includes levels of ideology and morality, scientific and cultural qualities and other content, with a total of 9 questions; basic competitiveness includes interpersonal communication, concept of employment, physical and mental qualities and other capabilities extended from these, with a total of 8 questions; environmental competitiveness mainly refers to the family situation, including family income and family connections, with a total of 2 questions. The above questions are single-choice questions, using Likert's five-level scale with the score indicating the degree of conformity, with 1 representing "non-conformity" and 5 representing "conformity". The reliability coefficients of the three levels are $0.892,0.913$, and 0.840 , respectively, indicating that they all have high reliability. In addition, factor analysis shows that the KMOs of the three layers are $0.878,0.890$, and 0.912 , respectively, and the significance of the Bartlett spherical test is less than 0.01 , indicating good structural validity. 


\subsection{Sample}

In this study, a total of 331 questionnaires were distributed to 2019 college graduates of Beijing Union University, 19 invalid questionnaires were eliminated, and 312 valid questionnaires were collected, making $94.26 \%$ of the questionnaires valid. Among these, in terms of gender there are relatively more females, accounting for $60.26 \%$, while males account for $39.74 \%$; in terms of major, $58.97 \%$ of the subjects fall in liberal arts, and $41.03 \%$ of the respondents fall in science; in terms of political affiliation, the number of non-Party members accounted for $82.69 \%$, and the number of party members accounted for $17.31 \%$. In terms of the registered permanent residence, students from Beijing accounted for $73.4 \%$, while students from outside of Beijing accounted for $26.6 \%$. In terms of the habitual residence, $72.76 \%$ live in city and $27.24 \%$ live in rural areas. (See Table 1).

Table 1. Basic statistics of sample

\begin{tabular}{|c|c|c|c|}
\hline Variable & Option & Frequency & Percentage (\%) \\
\hline \multirow{2}{*}{ Gender } & Male & 124 & 39.74 \\
\hline & Female & 188 & 60.26 \\
\hline \multirow{2}{*}{ Major } & Liberal arts & 184 & 58.97 \\
\hline & Science & 128 & 41.03 \\
\hline \multirow{2}{*}{ Political affiliation } & Party member & 54 & 17.31 \\
\hline & Non-Party member & 258 & 82.69 \\
\hline \multirow{2}{*}{ Registered permanent residence } & Beijing & 229 & 73.40 \\
\hline & Outside of Beijing & 83 & 26.60 \\
\hline \multirow{2}{*}{ Habitual residence } & City & 227 & 72.76 \\
\hline & Rural area & 85 & 27.24 \\
\hline
\end{tabular}

\section{Investigation Results and Analysis}

\subsection{Status Quo of Employment Competitiveness}

\subsubsection{Descriptive Statistics on Employment Competitiveness}

\subsubsection{Overall Employment Competitiveness}

As shown in Figure 1, the mean of employment competitiveness of graduates is 3.508, of which the means of basic competitiveness and core competitiveness are higher than the overall employment competitiveness, and the mean of environmental competitiveness is lower than the mean of overall employment competitiveness. This shows that: Firstly, the overall employment competitiveness of the 2019 college graduates of Beijing Union University is at a general level; secondly, in terms of environmental competitiveness of college graduates, their individual family competitiveness is also relatively weak; thirdly, the core competitiveness of college graduates is lower than their basic competitiveness, therefore, graduates should focus on improving their level of core competitiveness.

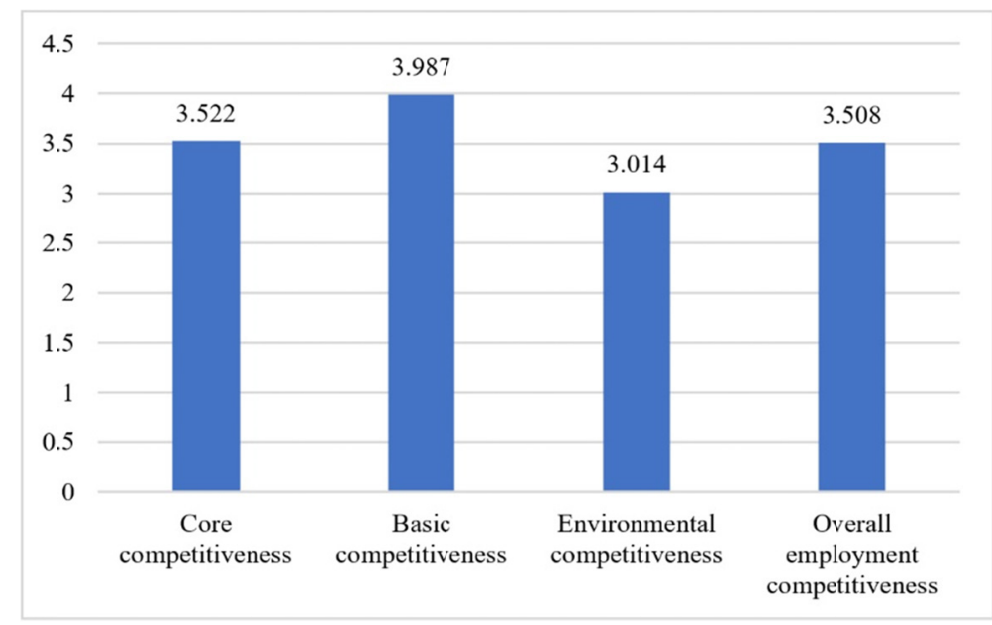

Figure 1. The mean of overall employment competitiveness 


\subsubsection{Core Competitiveness}

The survey shows that the mean of core competitiveness of graduates is 3.522 , which is at a general level. In terms of the nine aspects of evaluating core competitiveness (see Figure 2), "work experience" has the largest mean value of 4.516; "innovative spirit" has the second highest value of 4.343, while "entrepreneurial ability" has the smallest mean value of 1.769 , only accounting for half of the mean of core competitiveness, indicating that graduates have a sense of innovation which they will explore and make attempts, but they lack innovative and entrepreneurial abilities.

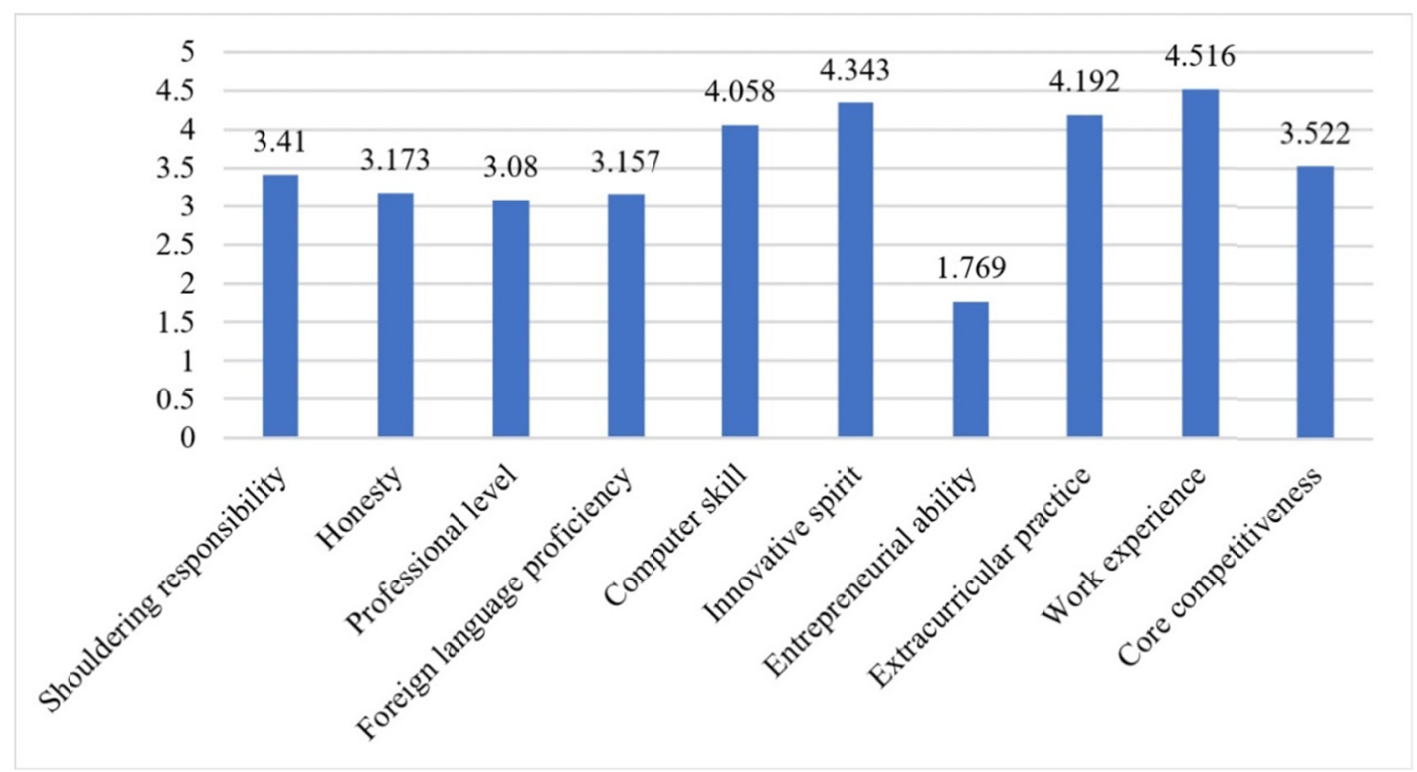

Figure 2. The mean of employment competitiveness at the level of core competitiveness

\subsubsection{Basic Competitiveness}

According to the statistical results of basic competitiveness of graduates, the mean of basic competitiveness of the 2019 graduates of Beijing Union University is 3.987, which is at a relatively high level. Specifically, in terms of the eight aspects for measuring the basic competitiveness of graduates (see Figure 3), the means of six aspects are higher than the mean of basic competitiveness, and the means of two aspects are lower than the mean of basic competitiveness. "Physical condition" has the highest mean of 4.554; "team spirit" has the lowest mean of 4.433 ; in addition, "job attitude" has the lowest mean of 2.535 , indicating that most graduates are unwilling to work in small towns or rural areas, and they hope to stay in big cities such as Beijing and Shanghai.

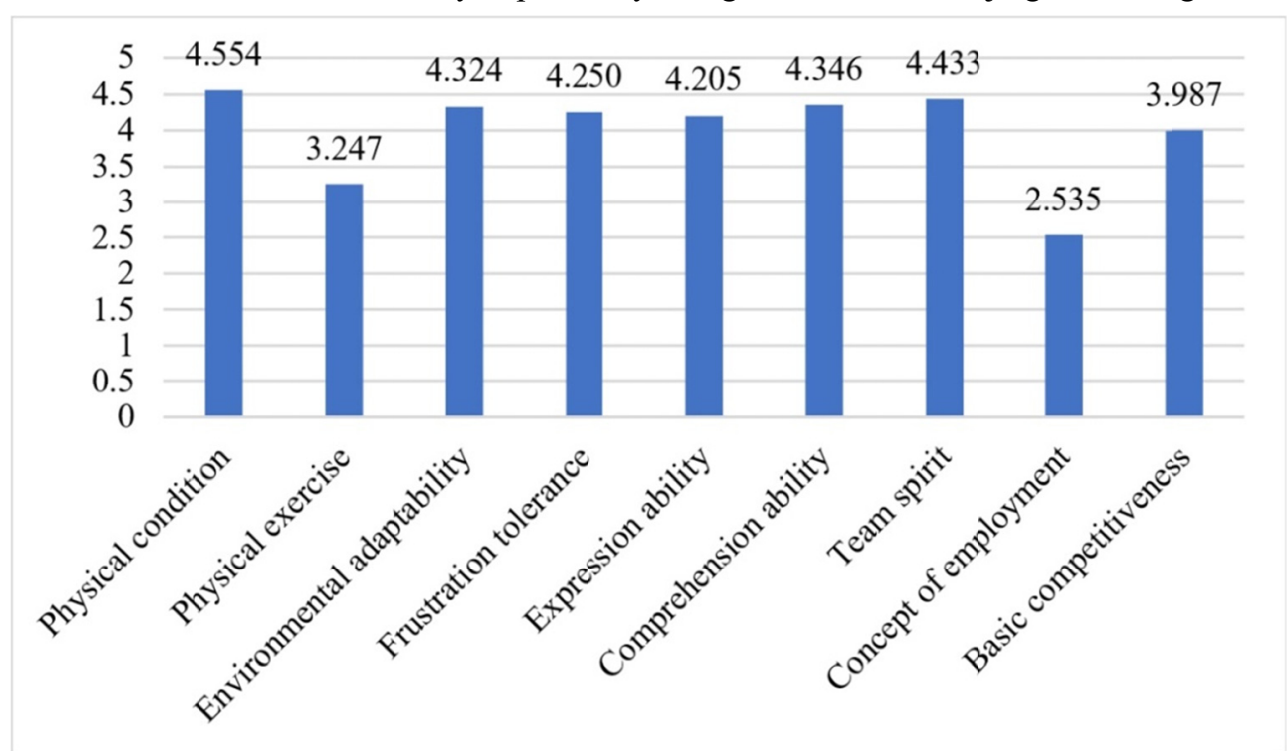

Figure 3. The mean of employment competitiveness at the level of basic competitiveness 


\subsubsection{Environmental Competitiveness}

As shown in Figure 4, the overall mean of environmental competitiveness is 3.014, of which the mean of "economic income" is higher than the mean of environmental competitiveness, which is 3.554 , indicating that some students have better family conditions and their lives are wealthier. However, the mean of "interpersonal relationship" is lower than the mean of environmental competitiveness, which is 2.474 at a relatively low level, indicating that family members and relatives cannot provide much help at the stage of searching for a job.

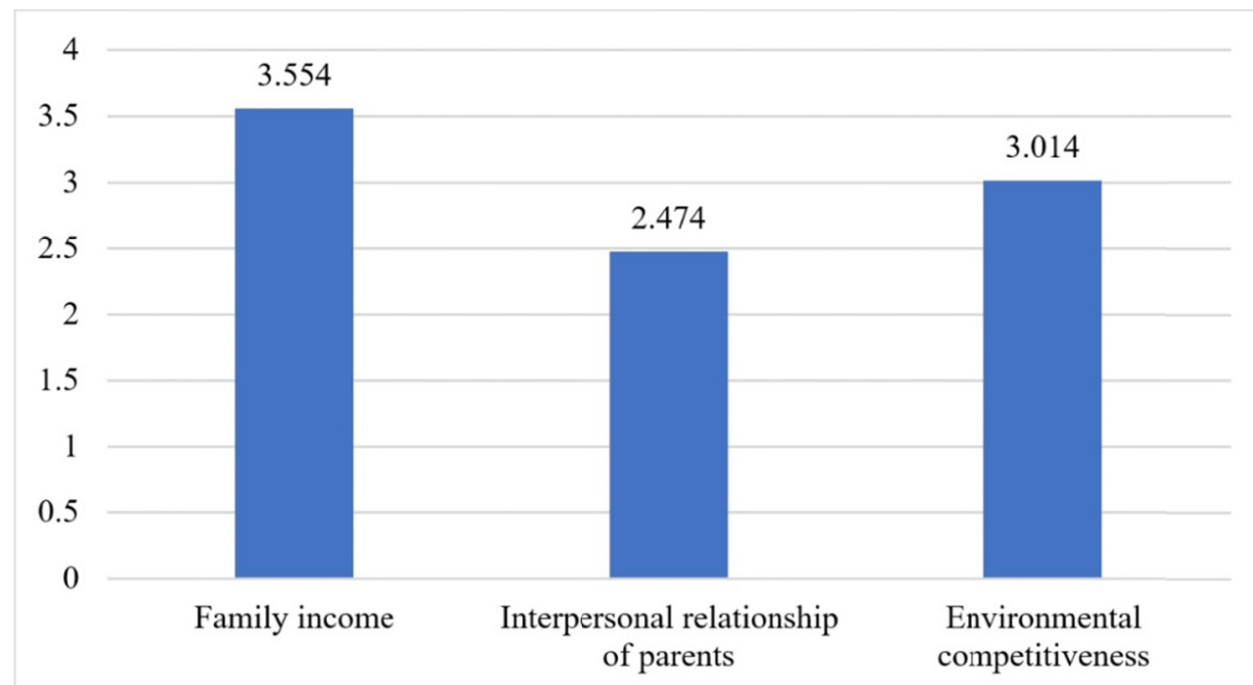

Figure 4. The mean of employment competitiveness at the level of environmental competitiveness

\subsection{Comparative Analysis of Differences in Employment Competitiveness}

In order to further understand the similarities and differences in employment competitiveness, and carry out targeted employment training, this paper conducts a comparative analysis of employment competitiveness of graduates based on demographic characteristics.

\subsubsection{Core Competitiveness}

As shown in Table 2, when gender is used as an independent variable, there was a significant difference between males and females in shouldering responsibility, professional level, and foreign language proficiency $(\mathrm{P}<0.05)$. By comparing the means, it is found that although the professional level and foreign language proficiency of males are lower than that of females, they are better than females at shouldering responsibility.

Table 2. Comparison of gender differences at the level of core competitiveness

\begin{tabular}{cccccc}
\hline & \multicolumn{2}{c}{ Gender $(\mathrm{M} \pm \mathrm{SD})$} & & \multirow{2}{*}{$\mathrm{t}$} \\
\cline { 2 - 3 } & Male & Female & & \\
\hline Shouldering responsibility & $3.55 \pm 1.00$ & $3.32 \pm 0.86$ & & 2.166 & $0.031^{*}$ \\
Honesty & $3.19 \pm 0.91$ & $3.16 \pm 0.91$ & & 0.324 & 0.746 \\
Professional level & $2.92 \pm 1.07$ & $3.19 \pm 1.12$ & -2.095 & $0.037^{*}$ \\
Foreign language proficiency & $2.75 \pm 1.14$ & $3.43 \pm 1.17$ & -5.033 & $0.000^{* *}$ \\
Computer skill & $4.15 \pm 0.93$ & $4.00 \pm 0.77$ & & 1.449 & 0.149 \\
Innovative spirit & $4.35 \pm 0.76$ & $4.34 \pm 0.51$ & 0.255 & 0.799 \\
Entrepreneurial ability & $1.90 \pm 1.27$ & $1.68 \pm 1.24$ & & 1.536 & 0.126 \\
Extracurricular practice & $4.26 \pm 0.85$ & $4.15 \pm 0.84$ & & 1.116 & 0.265 \\
Work experience & $4.54 \pm 1.06$ & $4.50 \pm 1.04$ & & 0.332 & 0.74 \\
\hline
\end{tabular}

$* \mathrm{p}<0.05 * * \mathrm{p}<0.01$

As shown in Table 3, when the political affiliation is used as an independent variable, it shows that Party members and non-Party members have significant differences in their professional level and foreign language proficiency. By comparing the means, the professional level and foreign language proficiency of Party members are stronger than those of non-Party members. This is consistent with the fact, because one of the conditions for becoming a Party member is to have excellent academic performance. 
Table 3. Comparison of political status differences at the level of core competitiveness

\begin{tabular}{cccccc}
\hline & \multicolumn{2}{c}{ Political status $(\mathrm{M} \pm \mathrm{SD})$} & \multirow{2}{*}{$\mathrm{t}$} & $\mathrm{P}$ \\
\cline { 2 - 3 } & Party member & Non-party member & & & \\
\hline Shouldering responsibility & $3.28 \pm 0.98$ & $3.44 \pm 0.91$ & & -1.164 & 0.245 \\
Honesty & $3.19 \pm 0.93$ & $3.17 \pm 0.90$ & & 0.108 & 0.914 \\
Professional level & $3.67 \pm 0.99$ & $2.96 \pm 1.09$ & & 4.698 & $0.000^{* *}$ \\
Foreign language proficiency & $3.52 \pm 1.13$ & $3.08 \pm 1.21$ & 2.556 & $0.012^{*}$ \\
Computer skill & $3.94 \pm 0.98$ & $4.08 \pm 0.80$ & -1.096 & 0.274 \\
Innovative spirit & $4.30 \pm 0.82$ & $4.35 \pm 0.57$ & -0.611 & 0.542 \\
Entrepreneurial ability & $1.81 \pm 1.18$ & $1.76 \pm 1.27$ & & 0.293 & 0.77 \\
Extracurricular practice & $4.30 \pm 0.74$ & $4.17 \pm 0.87$ & & 0.994 & 0.321 \\
Work experience & $4.61 \pm 0.83$ & $4.50 \pm 1.09$ & & 0.732 & 0.465 \\
\hline
\end{tabular}

${ }^{*} \mathrm{p}<0.05 * * \mathrm{p}<0.01$

In addition, graduates from different registered permanent residences, habitual residences, and majors have no significant differences in core competencies.

\subsubsection{Basic Competitiveness}

As shown in Table 4, when gender is used as an independent variable, there is only difference in the physical exercise $(\mathrm{P}<0.05)$. The mean of male students in physical exercise is 3.86 , and that for female students is 2.84 , indicating that male students is better than female students on physical exercise.

Table 4. Comparison of gender differences at the level of basic competitiveness

\begin{tabular}{|c|c|c|c|c|}
\hline & \multicolumn{2}{|c|}{ Gender $(\mathrm{M} \pm \mathrm{SD})$} & \multirow{2}{*}{$\mathrm{t}$} & \multirow{2}{*}{$\mathrm{P}$} \\
\hline & Male & Female & & \\
\hline Physical condition & $4.52 \pm 1.07$ & $4.58 \pm 0.98$ & -0.543 & 0.588 \\
\hline Physical exercise & $3.86 \pm 1.26$ & $2.84 \pm 1.50$ & 6.475 & $0.000 * *$ \\
\hline Environmental adaptability & $4.38 \pm 0.53$ & $4.29 \pm 0.48$ & 1.548 & 0.123 \\
\hline Frustration tolerance & $4.30 \pm 0.82$ & $4.22 \pm 0.59$ & 0.947 & 0.345 \\
\hline Expression ability & $4.13 \pm 0.60$ & $4.26 \pm 0.60$ & -1.821 & 0.07 \\
\hline Comprehension ability & $4.31 \pm 0.48$ & $4.37 \pm 0.57$ & -0.87 & 0.385 \\
\hline Team spirit & $4.45 \pm 0.63$ & $4.42 \pm 0.65$ & 0.425 & 0.671 \\
\hline Concept of employment & $2.48 \pm 1.05$ & $2.57 \pm 1.22$ & -0.762 & 0.447 \\
\hline
\end{tabular}

$* \mathrm{p}<0.05 * * \mathrm{p}<0.01$

It can be seen from Table 5 that when the major is used as the independent variable, students from different major differ in physical exercise $(\mathrm{P}<0.05)$. Students of science perform better than students of liberal arts in physical exercise. This can also indirectly prove that male students perform better than female students in physical exercise, because mainly male students major in science, while mostly female students in liberal arts.

Table 5. Comparison of major category differences at the level of basic competitiveness

\begin{tabular}{|c|c|c|c|c|}
\hline & \multicolumn{2}{|c|}{ Major $(\mathrm{M} \pm \mathrm{SD})$} & \multirow{2}{*}{$\mathrm{t}$} & \multirow{2}{*}{$\mathrm{P}$} \\
\hline & Liberal arts & Science & & \\
\hline Physical condition & $4.53 \pm 1.03$ & $4.59 \pm 0.98$ & -0.457 & 0.648 \\
\hline Physical exercise & $3.03 \pm 1.49$ & $3.55 \pm 1.46$ & -3.068 & $0.002 * *$ \\
\hline Environmental adaptability & $4.28 \pm 0.46$ & $4.39 \pm 0.55$ & -1.912 & 0.057 \\
\hline Frustration tolerance & $4.23 \pm 0.60$ & $4.27 \pm 0.80$ & -0.477 & 0.634 \\
\hline Expression ability & $4.20 \pm 0.62$ & $4.21 \pm 0.58$ & -0.142 & 0.887 \\
\hline Comprehension ability & $4.35 \pm 0.58$ & $4.34 \pm 0.48$ & 0.068 & 0.946 \\
\hline Team spirit & $4.38 \pm 0.65$ & $4.51 \pm 0.61$ & -1.74 & 0.083 \\
\hline Concept of employment & $2.55 \pm 1.19$ & $2.52 \pm 1.10$ & 0.25 & 0.802 \\
\hline
\end{tabular}

$* \mathrm{p}<0.05 * * \mathrm{p}<0.01$ 
When political affiliation is used as an independent variable, the $\mathrm{P}$ value of all items is greater than 0.05 , indicating that the differences in basic competitiveness of graduates with different political affiliations are not significant.

As shown in Table 6, when the registered permanent residence is used as an independent variable, there are differences in environmental adaptability and the concept of employment $(\mathrm{P}<0.05)$. In environmental adaptability, the mean of graduates from outside of Beijing is higher than that of graduates from Beijing, indicating that graduates from outside of Beijing are better at adapting to new environments than graduates from Beijing. In addition, for graduates from Beijing are accustomed to living in big cities, graduates from outside of Beijing are more likely to get used to work in small towns or rural areas than graduates from Beijing.

Table 6. Comparison of differences of registered permanent residence at the level of basic competitiveness

\begin{tabular}{|c|c|c|c|c|}
\hline & \multicolumn{2}{|c|}{ Registered permanent residence $(\mathrm{M} \pm \mathrm{SD})$} & \multirow{2}{*}{$\mathrm{t}$} & \multirow{2}{*}{$\mathrm{P}$} \\
\hline & Beijing & Outside of Beijing & & \\
\hline Physical condition & $4.52 \pm 1.05$ & $4.64 \pm 0.92$ & -0.882 & 0.378 \\
\hline Physical training & $3.23 \pm 1.49$ & $3.30 \pm 1.52$ & -0.386 & 0.7 \\
\hline Environmental adaptability & $4.28 \pm 0.49$ & $4.46 \pm 0.50$ & -2.856 & $0.005^{* *}$ \\
\hline Frustration tolerance & $4.25 \pm 0.60$ & $4.25 \pm 0.90$ & -0.039 & 0.969 \\
\hline Expression ability & $4.21 \pm 0.59$ & $4.19 \pm 0.63$ & 0.218 & 0.828 \\
\hline Comprehension ability & $4.32 \pm 0.51$ & $4.41 \pm 0.61$ & -1.159 & 0.249 \\
\hline Team spirit & $4.41 \pm 0.53$ & $4.51 \pm 0.86$ & -0.99 & 0.324 \\
\hline Concept of employment & $2.34 \pm 1.11$ & $3.07 \pm 1.10$ & -5.151 & $0.000 * *$ \\
\hline
\end{tabular}

$* \mathrm{p}<0.05 * * \mathrm{p}<0.01$

As shown in Table 7, when the habitual residence is used as an independent variable, graduates from different habitual residences have significant differences in environmental adaptability and concept of employment $(\mathrm{P}<0.05)$. Similarly, when comparing the results with that of the registered permanent residence, graduates who live in rural areas perform better than the graduates living in the city in environmental adaptability and concept of employment.

Table 7. Comparison of habitual residence differences at the level of basic competitiveness

\begin{tabular}{|c|c|c|c|c|}
\hline & \multicolumn{2}{|c|}{ Habitual residence $(\mathrm{M} \pm \mathrm{SD})$} & \multirow{2}{*}{$\mathrm{t}$} & \multirow{2}{*}{$\mathrm{P}$} \\
\hline & City & Rural areas & & \\
\hline Physical condition & $4.54 \pm 1.04$ & $4.60 \pm 0.95$ & -0.485 & 0.628 \\
\hline Physical training & $3.22 \pm 1.49$ & $3.33 \pm 1.54$ & -0.595 & 0.552 \\
\hline Environmental adaptability & $4.26 \pm 0.49$ & $4.48 \pm 0.50$ & -3.436 & $0.001 * *$ \\
\hline Frustration tolerance & $4.21 \pm 0.65$ & $4.35 \pm 0.77$ & -1.509 & 0.134 \\
\hline Expression ability & $4.23 \pm 0.57$ & $4.13 \pm 0.67$ & 1.36 & 0.175 \\
\hline Comprehension ability & $4.35 \pm 0.52$ & $4.34 \pm 0.59$ & 0.1 & 0.921 \\
\hline Team spirit & $4.43 \pm 0.54$ & $4.45 \pm 0.85$ & -0.199 & 0.842 \\
\hline Concept of employment & $2.36 \pm 1.13$ & $3.00 \pm 1.09$ & -4.56 & $0.000 * *$ \\
\hline
\end{tabular}

$* \mathrm{p}<0.05 * * \mathrm{p}<0.01$

\subsubsection{Environmental Competitiveness}

The analysis shows that when the independent variable is the registered permanent residence or habitual residence, graduates from Beijing and graduates living in cities have relatively higher family income (see Tables 8 and 9). Compared with graduates who are from families with difficult financial situations, graduates who live a wealthy live have an advantage in developing professional ability, and they have clearer plans. In addition, families with high incomes have relatively high investments in their children's education, which promotes the employment competitiveness of graduates. 
Table 8. Comparison of differences of registered permanent residence at the level of environmental competitiveness

\begin{tabular}{cccccc}
\hline & \multicolumn{2}{c}{ Registered permanent residence $(\mathrm{M} \pm \mathrm{SD})$} & & \multirow{2}{*}{$\mathrm{P}$} \\
\cline { 2 - 3 } & Beijing & Outside of Beijing & & \\
\hline Family income & $3.69 \pm 1.05$ & $3.19 \pm 1.17$ & & 3.368 & $0.001^{* *}$ \\
Interpersonal relationship of parents & $2.49 \pm 1.30$ & $2.42 \pm 1.31$ & & 0.43 & 0.667 \\
\hline$* \mathrm{p}<0.05^{* *} \mathrm{p}<0.01$ & & & &
\end{tabular}

Table 9. Comparison of habitual residence differences at the level of environmental competitiveness

\begin{tabular}{cccccc}
\hline & \multicolumn{2}{c}{ Habitual residence $(\mathrm{M} \pm \mathrm{SD})$} & \multirow{2}{*}{$\mathrm{t}$} & $\mathrm{P}$ \\
\cline { 2 - 3 } & City & Rural areas & & \\
\hline Family income & $3.70 \pm 1.03$ & $3.15 \pm 1.22$ & & 3.649 & $0.000^{* *}$ \\
Interpersonal relationship of parents & $2.51 \pm 1.29$ & $2.38 \pm 1.33$ & & 0.813 & 0.417 \\
\hline
\end{tabular}

$* \mathrm{p}<0.05 * * \mathrm{p}<0.01$

\section{Research Conclusions and Recommendations for Countermeasures}

\subsection{Conclusion}

The analysis results of this paper show that the overall level of employment competitiveness of 2019 graduates of Beijing Union University is not high. Among the three aspects that constitute employment competitiveness, the level of environmental competitiveness is the weakest, the core competitiveness is second, and the basic competitiveness is the highest. In basic competitiveness, graduates have relatively strong environmental adaptability and team spirit, and the mean of both is far higher than that of the basic competitiveness. In addition, although females do less exercise than males, graduates generally have good physical fitness.

In core competitiveness, graduates perform with stronger enthusiasm, they participate in school activities and extracurricular practice during the school year, and they also have rich internship experiences. Although graduates are generally innovative and willing to explore and make attempts, students who really put it into practice are few. Professional level and foreign language proficiency of graduates are not strong, and many students said that they do not complete their homework diligently. In environmental competition, the family conditions of graduates are good in general, but when students are looking for work, family members and relatives cannot provide much help. In addition, the interviews reveal that most graduates are reluctant to work in small towns or rural areas, and they hope to stay in big cities such as Beijing, Shanghai and Guangzhou to develop. They pay attention to salary when making career choices, and they think that employment difficulties are mainly due to the low popularity of school, large number of graduates and lacking test-taking skills.

The results of the comparative analysis of demographic characteristics show that: First, there is difference on physical exercise among graduates with different major and gender. Specifically, male or graduates in science pay more attention to physical exercise; second, registered permanent residence and habitual residence have an impact on their environmental adaptability, concept of employment and family income. In family income, the income of families in Beijing and cities are relatively high. In environmental adaptability and the concept of employment, graduates from outside of Beijing and graduates from rural areas are relatively strong, and they are more willing to work in small cities. Third, the foreign language proficiency and professional level of graduates are related to gender and political affiliation. Among these, the professional level and foreign language proficiency of female students are higher than those of male students. The professional level and foreign language proficiency of Party members are higher than those of non-Party members. Fourth, in shouldering responsibility, there are significant differences between males and females. Compared with females, males are more willing to take on more difficult tasks in a group.

\subsection{Countermeasures}

From the individual level of graduates, it is necessary that they not only improve their professional qualities and foreign language proficiency, but also focus on practical learning, and through practical experiences improve skills in analysis, expression, innovation, as well as environmental resilience. As a student, one must have a sense of active learning. As a teacher, one should pay attention to the class performance, homework completion, and internships of students. Physical exercise should be strengthened while studying. Schools can develop exercise plans and regularly check the activities undertaken by students. In the process of choosing a career, 
graduates must establish a correct outlook on career choices and accurately assess their own abilities, and determine their employment direction based on their own strengths and advantages, combined with the employment situation and career development prospects. At the same time, students should master job hunting skills, especially revising their resume according to different companies and positions, rather than keeping their resume the same.

From the perspective of the school, we must first strengthen education for innovation and entrepreneurship. Through the improvement of the innovation and entrepreneurship curriculum system, awareness of innovation and entrepreneurship of students will be cultivated, and the ability to innovate and engage in entrepreneurship will be improved. At the same time, school-enterprise cooperation should be strengthened so that students can apply what they have learned. Secondly, the curriculum system should be improved by focusing on experiential teaching. For example, after the recruitment theory course is held, a simulated job fair shall be held to allow students to further understand company interview processes during the simulation recruitment and interview process, and better grasp practical interviewing skills. In addition, schools should provide students with comprehensive and multi-level employment guidance, including employment policy consultation, employment problem solving, and arrange graduates to participate in job fairs. In this regard, the school should focus on cultivating a professional team of employment guidance teachers.

\section{References}

Beverley, O. (2015). Redefining graduate employability and work-integrated learning: Proposals for effective higher education in disrupted economies. Journal of Teaching and Learning for Graduate Employability, $6(1), 56-65$.

Cao, Y. X. (2017). Analysis of Factors Affecting Employment of Private College Graduates and Countermeasures. Education \& Vocation, 17, 65-69. https://doi.org/10.13615/j.cnki.1004-3985.2017.17.013

Chen, L. L. (2019). Research on the Status Quo of Employment Competitiveness of Higher Vocational Graduates. The Guide of Science \& Education, 8(1), 157-158. https://doi.org/10.16400/j.cnki.kjdks.2019.08.077

Chen, X. H. (2018). Investigation and Analysis of the Status Quo of the Employment Ability of Vocational College Students. Journal of Guangdong Polytechnic Normal University, 39(6), 97-103. https://doi.org/10.13408/j.cnki.gjsxb.2018.06.018

Green, A. E., De Hoyos, M., Barnes, S. A., Owen, D., Baldauf, B., \& Behle, H. (2013). Literature review on employability, inclusion and ICT, report 1: The concept of employability, with a specific focus on young people, older workers and migrants. Publications Office of the European Union.

Li, J., \& Cheng, Y. H. (2018). Analysis of the Status Quo of the Employment of Higher Vocational College Students in Hebei Province-From the Perspective of Made in China 2025. Think Tank Era, 47,103-104.

Li, Y. N. (2019). An Empirical Study on the Status Quo of Employment Competitiveness of College Students with Financial Difficulties and the Promotion Strategy-Based on the Survey of Four Universities in Hebei Province. Think Tank Era, 15, 11-12, 16.

Liu, X. Y., \& Hu, J. G. (2008). Empirical Analysis of Factors Affecting Employment of College Graduates Based on Regression Model. Journal of Jiangxi University of Finance and Economics, 2, 115-120.

Lou, X. J., Zhou, S. H., \& Wu, L.Y. (2005). Analysis of College Students' Employment Competitiveness. Exploring Education Development, 13, 49-52. https://doi.org/10.14121/j.cnki.1008-3855.2005.13.013

Ma, M. Y., \& Peng, B. (2018). Discussion on the Status Quo and Cultivation of College Students' Employment Competitiveness in Liaoning Province. Modern Economic Information, 23, 399.

Shao, C. Y., Zhao, H. B., Huang, X. J., \& Cao, Y. (2019). Status Quo and Influencing Factors of Employment Competitiveness of Applied Talents in Universities. Industrial Innovation, 1, 56-57.

Zhao, J. (2015). An Empirical Study of College Students' Employment Competitiveness Based on Factor Analysis-Taking Successful Employment of College Students as a Sample. Modern Education Management, 2, 119-123. https://doi.org/10.16697/j.cnki.xdjygl.2015.02.023

\section{Copyrights}

Copyright for this article is retained by the author(s), with first publication rights granted to the journal.

This is an open-access article distributed under the terms and conditions of the Creative Commons Attribution license (http://creativecommons.org/licenses/by/4.0/). 